\title{
Inosine as a Tool to Understand and Treat Central Nervous System Disorders: A Neglected Actor?
}

\author{
Francisney Pinto Nascimento ${ }^{1 *}$, Sérgio José Macedo-Júnior ${ }^{2}$, \\ Fernanda Rocha Lapa-Costa ${ }^{3}$, Fernando Cezar-dos-Santos ${ }^{1}$ and Adair R. S. Santos ${ }^{4}$ \\ ${ }^{1}$ Programa de Pós-Graduação em Biociências, Laboratório de Neurofarmacologia Clínica, Faculdade de Medicina, \\ Universidade Federal da Integração Latino-Americana, Foz do Iguaçu, Brazil, ${ }^{2}$ Centro de Inovação e Ensaios Pré-clínicos, \\ Florianópolis, Brazil, ${ }^{3}$ Faculdade de Farmácia, Universidade do Contestado, Concórdia, Brazil, ${ }^{4}$ Programa \\ de Pós-Graduação em Neurociências, Laboratório de Neurobiologia da Dor e Inflamação, Universidade Federal de Santa \\ Catarina, Florianópolis, Brazil
}

OPEN ACCESS

Edited by:

Santiago Perez-Lloret,

Consejo Nacional de Investigaciones Científicas y Técnicas (CONICET),

Argentina

Reviewed by:

George Hasko,

Columbia University, United States

Stefania Ceruti,

University of Milan, Italy

Carla Denise Bonan,

Pontifical Catholic University of Rio

Grande do Sul, Brazil

${ }^{*}$ Correspondence:

Francisney Pinto Nascimento

francisney.nascimento@unila.edu.br

tIn memoriam

Specialty section:

This article was submitted to

Neuropharmacology,

a section of the journal

Frontiers in Neuroscience

Received: 30 April 2021

Accepted: 20 July 2021

Published: 24 August 2021

Citation:

Nascimento FP,

Macedo-Júnior SJ, Rocha Lapa-Costa F, Cezar-dos-Santos F and Santos ARS (2021) Inosine as

a Tool to Understand and Treat Central Nervous System Disorders:

A Neglected Actor?

Front. Neurosci. 15:703783.

doi: 10.3389/fnins.2021.703783
Since the 1970s, when ATP was identified as a co-transmitter in sympathetic and parasympathetic nerves, it and its active metabolite adenosine have been considered relevant signaling molecules in biological and pathological processes in the central nervous system (CNS). Meanwhile, inosine, a naturally occurring purine nucleoside formed by adenosine breakdown, was considered an inert adenosine metabolite and remained a neglected actor on the purinergic signaling scene in the CNS. However, this scenario began to change in the 1980s. In the last four decades, an extensive group of shreds of evidence has supported the importance of mediated effects by inosine in the CNS. Also, inosine was identified as a natural trigger of adenosine receptors. This evidence has shed light on the therapeutic potential of inosine on disease processes involved in neurological and psychiatric disorders. Here, we highlight the clinical and preclinical studies investigating the involvement of inosine in chronic pain, schizophrenia, epilepsy, depression, anxiety, and in neural regeneration and neurodegenerative diseases, such as Parkinson and Alzheimer. Thus, we hope that this review will strengthen the knowledge and stimulate more studies about the effects promoted by inosine in neurological and psychiatric disorders.

Keywords: adenosine, uric acid, pain, depression, Alzheimer, Parkinson, memory, neural regeneration

\section{INTRODUCTION}

The history of purine nucleosides began and gained therapeutic importance in 1929 with a paper published by Drury and Szent-Gyorgyi, who described the potent actions of purine on the heart and blood vessels, nucleotides and nucleosides, ATP, and adenosine (Burnstock, 2006). In the 1970s, the hypothesis that adenosine $5^{\prime}$-triphosphate (ATP) was a transmitter in non-adrenergic, non-cholinergic (NANC) inhibitory nerves was confirmed, and ATP was identified as a co-transmitter in sympathetic and parasympathetic nerves. The aforementioned supported the concept of purinergic neurotransmission and enhanced interest in the role of purine nucleosides in the brain and spinal cord, which was reported in various studies (North and Verkhratsky, 2006; Burnstock, 2007, 2020). In the subsequent decades, a number of studies demonstrated that adenosine can act as a signaling molecule essential for biological and pathological processes of the central nervous system. At 
the same time, evidence showed that adenosine metabolism generates inosine, a metabolite with possible biological and pharmacological effects in the peripheral and central nervous systems (see Figure 1). Inosine, which was first considered an inert adenosine metabolite after being used as a nutritional supplement to improve muscle function in trained endurance runners (Williams et al., 1990; McNaughton et al., 1999), has gained special attention due to a few studies in the 1990s that demonstrated that inosine is a signaling molecule that can modulate the immune system when produced under stressful conditions, such as those that occur during injury, ischemia, and inflammation. In these situations, an elevation in extracellular inosine concentrations due to high adenosine metabolism levels caused by an increase in adenosine deaminase expression was demonstrated (Haskó et al., 2000; Garcia Soriano et al., 2001; Liaudet et al., 2002; Eltzschig et al., 2006; Eltzschig, 2009; Fredholm et al., 2011).

The theory that inosine contributes to, or mediates adenosine effects is reinforced by studies that consider inosine as a natural trigger of adenosine receptors (Jin et al., 1997; Tilley et al., 2000;
Gomez and Sitkovsky, 2003; Haskó et al., 2004; Eltzschig et al., 2006). These receptors were first formally recognized by Burnstock in 1978 and are subdivided into four subtypes: $A_{1}, A_{2 A}, A_{2 B}$, and $A_{3}$. The adenosine $A_{1}$ and $A_{3}$ receptors preferentially interact with members of the Gi/o family of $G$ proteins, lowering the intracellular levels of cyclic adenosine monophosphate (cAMP), whereas the adenosine $A_{2 A}$ and $A_{2 B}$ receptors interact with members of the Gs family of $G$ proteins, elevating intracellular cAMP (Ralevic and Burnstock, 1998; Eltzschig et al., 2006). Inosine binds to the adenosine receptors with affinities that are typically lower than that of adenosine. Although direct binding of inosine to adenosine $\mathrm{A}_{2 \mathrm{~B}}$ receptor has not been demonstrated, there is convincing evidence suggesting that inosine interacts functionally with all four adenosine receptor subtypes to elicit various effects depending on the species' biological context (Nascimento et al., 2010; Kaster et al., 2013; Lapa et al., 2013; Muto et al., 2014; Doyle et al., 2017, 2018; Junqueira et al., 2017).

In the last four decades, a number of studies have shown that receptor-mediated inosine effects involve decreased

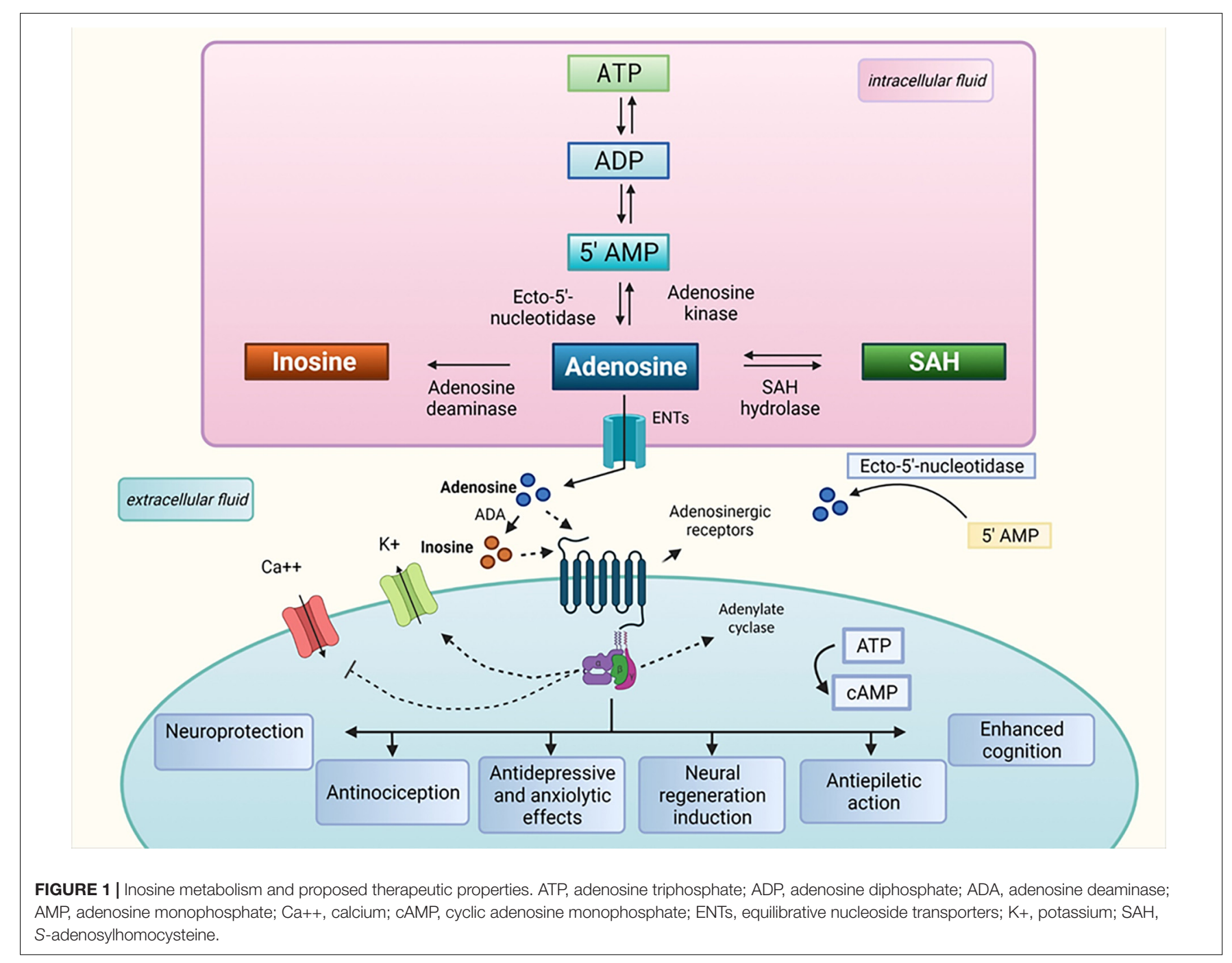


inflammation, neuroprotection/neuroregeneration, and axon outgrowth in the central nervous system, which elicits scavenger activities and immunomodulatory effects. These effects directly reflect the therapeutic potential observed in pathological processes involved in chronic pain, schizophrenia, depression, anxiety, and neurodegenerative diseases such as Parkinson's and Alzheimer's disease (for a summary see Table 1). Given the increasing interest in the pharmacological potential of inosine as a new alternative therapy for CNS diseases, this review will focus on inosine effects in preclinical and clinical studies and describe the "state of the art" of the scientific research panorama regarding this promising molecule.

\section{INOSINE AND PAIN}

Adenosinergic and purinergic ligands are well-known modulators of acute and chronic pain of different etiologies in animals and humans both centrally and at the periphery, displaying beneficial and sometimes deleterious roles in pain pathology (Sawynok, 1998; Sawynok and Liu, 2003; Adebiyi et al., 2019). Most studies evaluating the analgesic effect of adenosine or adenosine receptor agonists have shown that these substances are able to enhance the pain threshold. However, in some cases these drugs can facilitate pain transmission. These controversial findings are probably due to the distinct signaling and distribution of adenosine receptors. Adenosine $A_{1}$ and $A_{3}$

TABLE 1 | Summary of in vitro, preclinical and clinical studies that have demonstrated the therapeutic potential of inosine to treat neurological and psychiatric diseases.

\begin{tabular}{|c|c|c|c|c|c|}
\hline CNS disorder & Specie & Agent & $\begin{array}{l}\text { Dose/Concentration/ } \\
\text { Route }\end{array}$ & Effect & References \\
\hline Pain & Mice & Inosine & $\begin{array}{l}\text { 10-300 mg/kg/i.p. and } \\
\text { p.o. } 10 \mu \mathrm{g} / \mathrm{i.c.v.} / \mathrm{i} . t .\end{array}$ & $\begin{array}{l}\text { Inosine mediates reduction time of licking in the } \\
\text { formalin test, inhibition of glutamate-induced } \\
\text { nociception, reduction mechanical allodynia and } \\
\text { hyperalgesia }\end{array}$ & Nascimento et al., 2010 \\
\hline Pain & Mice & Inosine & 10 mg/kg/i.p. & $\begin{array}{l}\text { Inosine promotes antinociception through pertussis } \\
\text { toxin sensitive G-protein coupled receptors and } \\
\text { voltage gated } \mathrm{K}+\text { channel, large conductance } \\
\mathrm{Ca} 2+\text {-activated and ATP-sensitive K+ channels or } \\
\text { inactivation of voltage-gated Ca2+ channels }\end{array}$ & $\begin{array}{l}\text { Macedo-Junior et al., } \\
2013\end{array}$ \\
\hline Pain & Mice & Inosine & 10 and $100 \mathrm{mg} / \mathrm{kg} / \mathrm{i} . \mathrm{p}$ & $\begin{array}{l}\text { Inosine reduces flinching behavior induced by formalin } \\
\text { and systemic and central nociception in A1-wild type } \\
\text { mice }\end{array}$ & Nascimento et al., 2015 \\
\hline Pain & Mice & Inosine & 200-600 nmol/i.t. & $\begin{array}{l}\text { Inosine inhibits nociceptive response induced by } \\
\text { injection of capsaicin and increases ATP, ADP, AMP, } \\
\text { adenosine, inosine, hypoxanthine, xanthine, and uric } \\
\text { acid CSF levels }\end{array}$ & de Oliveira et al., 2016 \\
\hline $\begin{array}{l}\text { Learning and } \\
\text { memory }\end{array}$ & Rat & Inosine & 100 and 200 mg/kg/i.p. & $\begin{array}{l}\text { Learning and memory improvement, levels of } \\
\text { TNF-alpha reduction, antioxidant properties increment }\end{array}$ & Ruhal and Dhingra, 2018 \\
\hline Epilepsy & Rat & Inosine & $\begin{array}{l}500 \text { and } 1000 \mathrm{mg} / \mathrm{kg} \text {, } \\
\text { i.p. }\end{array}$ & $\begin{array}{l}\text { Inosine increases number and total time of } \\
\text { spike-waves discharges }\end{array}$ & Kovács et al., 2015a,b \\
\hline Epilepsy & Mice & Inosine & 400 nmol/4 $\mu$ l, i.c.v. & $\begin{array}{l}\text { Inosine protect against quinolinic-acid induced } \\
\text { seizures }\end{array}$ & Ganzella et al., 2011 \\
\hline Alzheimer & Rat & Inosine & 100 mg/kg, i.c.v. & $\begin{array}{l}\text { Inosine induces memory deficit prevention and AChE } \\
\text { activity reduction }\end{array}$ & Teixeira et al., 2020 \\
\hline Parkinson & $\begin{array}{l}\text { Dopaminergic } \\
\text { cells culture }\end{array}$ & Inosine & - & $\begin{array}{l}\mathrm{H}_{2} \mathrm{O}_{2} \text {-toxic effect on dopaminergic cells reduction, } \\
\text { indicators of free radical generation and oxidative } \\
\text { damage in MES 23.5-astrocytes co-cultures were } \\
\text { reduced }\end{array}$ & Cipriani et al., 2010 \\
\hline Parkinson & Human & Inosine & 500 mg; p.o. & $\begin{array}{l}\text { Average serum urate increment (more pronounced in } \\
\text { woman), reduction of motor symptoms in UPDRS } \\
\text { scale }\end{array}$ & $\begin{array}{l}\text { Schwarzschild et al., } \\
2019\end{array}$ \\
\hline $\begin{array}{l}\text { Neural } \\
\text { regeneration }\end{array}$ & Goldfish & Inosine & 50 and $100 \mu \mathrm{M}$ & $\begin{array}{l}\text { Inosine increases retinal ganglion cells neuronal } \\
\text { outgrowth and GAP-43 levels }\end{array}$ & Petrausch et al., 2000 \\
\hline $\begin{array}{l}\text { Neural } \\
\text { regeneration }\end{array}$ & $\begin{array}{c}\text { PC12 cells and } \\
\text { neuronal } \\
\text { embryonic cells } \\
\text { Sprague- } \\
\text { Dawley rat } \\
\text { fetuses }\end{array}$ & Inosine & $100 \mu \mathrm{M}-1 \mathrm{mM}$ & Inosine activates Mst3b kinase activity & Irwin et al., 2006 \\
\hline Anxiety & Mice & Inosine & 10 - 300 mg/kg, i.p. & $\begin{array}{l}\text { Inosine antagonizes anxiety-reducing actions of } \\
\text { benzodiazepines }\end{array}$ & Crawley et al., 1981 \\
\hline Anxiety & Mice & Inosine & $10-60$ mg/kg, s.c. & $\begin{array}{l}\text { Inosine presents anxiolytic effect in the Vogel-type } \\
\text { anti-conflict test }\end{array}$ & Okuyama et al., 1998 \\
\hline Depression & Mice & Inosine & 10 mg/kg, i.p. & $\begin{array}{l}\text { Inosine reduces mice immobility time in the forced } \\
\text { swim test and in the tale suspension test }\end{array}$ & Kaster et al., 2013 \\
\hline Depression & Human & $\begin{array}{l}\text { Inosine plasma } \\
\text { levels }\end{array}$ & - & $\begin{array}{l}\text { Inosine plasma levels are significantly higher in } \\
\text { individuals treated with antidepressant drugs when } \\
\text { compared to healthy individuals }\end{array}$ & Zhou et al., 2019 \\
\hline
\end{tabular}


receptors are coupled to inhibitory $G$ proteins while the $A_{2 A}$ and $A_{2 B}$ are coupled to stimulatory $G$ proteins. Further, the distribution of adenosine receptors in the periphery and central nervous system also are implicated in how these drugs act on pain modulation (Sawynok, 1998; Fredholm et al., 2011).

Reports detailing the antinociception - analgesia in pain animal models - exhibited by adenosine are not a novelty; however, until a few years ago, there were no studies evaluating the inosine antinociceptive effects. The first study that aimed to investigate the potential analgesic effects of inosine was published by our research group (Nascimento et al., 2010). This study used several acute pain animal models and demonstrated the antinociceptive action of this nucleoside in mice and rats. Inosine induced pain behavior reduction when given by oral, intraperitoneal, intratecal and intracerebroventricular, suggesting its systemic and central activity. Further, these findings suggest that inosine crosses the brain blood barrier (Nascimento et al., 2010). In addition, Nascimento and colleagues demonstrated that adenosine $A_{1}$ and $A_{2} A$ receptors are involved in the inosine antinociceptive effects. Also, this same study evaluated that inosine was able to reduce nociception in chronic neuropathic and inflammatory pain models. It suggests that inosine acts on neural and inflammatory mechanisms to reduce pain threshold. Some years later our group using pharmacological, biochemical and genetic approaches confirmed that inosine antinociceptive action was dependent on the adenosine $A_{1}$ receptor. Finally, this study proved that inosine is an endogenous agonist of adenosine $A_{1}$ receptor (Nascimento et al., 2015).

In addition to the involvement of adenosine receptors in the antinociceptive effects of inosine, Macedo-Junior et al. (2013) showed that the inosine effects involves the activation of voltage gated $\mathrm{K}^{+}$channels, large conductance $\mathrm{Ca}^{+}$and ATP-sensitive channels and the blockade of voltage-gated $\mathrm{Ca}^{+}$ channels. The involvement of these ion channels could occur through adenosine $A_{1}$ or $A_{2} A$ receptor activation. Peripherally, the inosine antinociception is mediated only by adenosine $A_{1}$ receptors but not by $\mathrm{A}_{2 \mathrm{~A}}$ (Macedo-Júnior et al., 2021).

Apart from the inosine binding to adenosine $A_{1}$ receptor to reduce pain, a study has shown that spinal administration of inosine increased the CFS levels of ATP, ADP, AMP, adenosine, hypoxanthine, xanthine, and uric acid (de Oliveira et al., 2016). These results suggest that inosine when reach the CNS could induce antinociceptive effect through these other nucleosides, because most of them have presented antinociceptive effects too (Sawynok and Liu, 2003).

Regarding the effects of inosine in humans, the clinical studies evaluating the involvement of inosine on pain are quite scarce. There are no clinical trial studies evaluating the analgesic effect of inosine in any kind of pain. However, there is some evidence that inosine could participate or be involved in clinical pain mechanisms. A study by Schmidt and coworkers found changes in extracellular inosine levels in patients experiencing pain. The authors suggest that shifts in neuronal and glial energy metabolism might be correlated with pain transmission mechanisms. CSF levels of inosine and other purines associated with ATP metabolism are significantly increased in chronic pain patients compared to control patients and are significantly correlated with pain intensity measured using a visual analog scale (Schmidt et al., 2010). Conversely, serum purine metabolites are increased in fibromyalgia patients (i.e., the dysregulation of pain pathways leading to central sensitization) compared to controls. In these patients, the magnitude of inosine detection was substantially higher than that of other metabolites (Fais et al., 2013).

Inosine is also a potential biomarker in plasma from patients experiencing non-traumatic chest pain or unstable angina due to potential acute cardiac ischemia/myocardial infarction (Farthing et al., 2007; Ameta et al., 2016). High levels of this nucleoside have already been reported in mouse hearts (Farthing et al., 2006) and in observational studies in humans (Al-Shamiri et al., 2009; Farthing et al., 2011). However, early evidence has shown that adenosine, but not inosine, may cause chest pain in healthy individuals. Then, the high levels of adenosine would be responsible for these inosine increments (Lagerqvist et al., 1990).

While the mechanisms mediated by inosine in nociceptive and neuropathic pain in animals have been studied in the last years and the results are encouraging, we need further studies to test and to better understand these actions. On the other hand, regarding clinical research on pain, there is a complete avenue to be explored and filled before we can say that this nucleoside could be useful in pain treatments.

\section{INOSINE AND COGNITION}

Very few studies have demonstrated that inosine can increase learning or memory, however, two recent non-clinical studies have shown promising results. The study by Ruhal and Dhingra (2018) used behavioral, biochemical, and histological techniques to demonstrate that inosine can induce learning and memory improvement in aged female rats. Inosine given by intraperitoneal route improved the learning and memory of aged rats in the Morris water maze and elevated plus-maze test. The reduced levels of TNF- $\alpha$ explain these results in the hippocampus and cerebral cortex. In addition, inosine increased the levels of GSH in the hippocampus and the activity of SOD in the cortex and hippocampus, and reduced the level of malondialdehyde, a marker of oxidative stress, in the hippocampus and cerebral cortex (Ruhal and Dhingra, 2018). Furthermore, inosine reduced the degeneration of cells in the CA1 region of the hippocampus, the most critical hippocampal region for memory acquisition, consolidation, and evocation (Ruhal and Dhingra, 2018).

Animal models of Alzheimer's disease (AD) have also been used to study the effects of inosine. In one study, AD was induced by streptozotocin (STZ), and the animals received inosine by intracerebroventricular route for 25 days (Teixeira et al., 2020). It is well demonstrated that administration of STZ in the brain induces changes similar to those found in $\mathrm{AD}$ such as learning and memory deficit, mitochondrial abnormalities, oxidative stress, neuronal cell damage and brain glucose metabolism alterations (Teixeira et al., 2020). This study demonstrated that inosine prevented memory deficits in the inhibitory avoidance task and the Y-maze test (Teixeira et al., 2020). In addition, inosine increased the serum levels of uric 
acid, a potent natural antioxidant. Teixeira et al. (2020) also demonstrated that inosine prevented an increase in $\mathrm{Na}^{+} / \mathrm{K}^{+}$ATPase and Mg-ATPase activities and decreased $\mathrm{Ca}^{2+}$-ATPase activity in the hippocampus and cerebral cortex induced by STZ. These actions on ion pumps can be related to the antioxidant effects of inosine and neurotransmitter release. Finally, inosine reduced acetylcholinesterase (AChE) activity and increased choline acetyltransferase (ChAT) activity. ChAT is the enzyme responsible for acetylcholine synthesis from choline and acetylCoA, and AChE is an enzyme that breaks down acetylcholine. Acetylcholine is the main neurotransmitter involved in memory processes, and studies have shown that changes in ChAT and AChE levels are correlated with cognitive decline in patients with AD (Gutierres et al., 2014; Pacheco et al., 2018). Another study demonstrated that inosine given by intraperitoneal route reduced the neurological severity score and improved non-spatial cognition and memory in mice undergoing a traumatic brain injury model. In the same study, inosine increased the expression of GAP-43, a marker of axonal growth, in the cerebral cortex (Dachir et al., 2014).

Furthermore, inosine effectively reduces the cognitive decline observed in an animal model induced by 12 Gy ionizing irradiation (Hou et al., 2007). Although there are very few studies evaluating the potential of inosine in learning and memory, the data from Ruhal and Dhingra (2018) have shown that inosine has potential and depends, at least in part, on the anti-inflammatory and antioxidative action of this nucleoside. Although these studies did not measure the inosine brain levels, it is clear the potential of inosine to change and treat cognition-related diseases. Then, this topic is an avenue to study and explore the potential therapeutic effects of inosine on cognition.

\section{INOSINE AND PARKINSON DISEASE}

In the last decade, several in vitro, in vivo, and clinical studies have demonstrated the potential of inosine to treat Parkinson's disease (PD). The studies by Cipriani et al. (2010) and McFarland et al. (2013) seem to be the fundamental studies that led to a series of other articles and a large clinical trial that evaluated inosine's ability to reduce symptoms and the progression of Parkinson's disease. Cipriani and colleagues showed that urate is an endogenous substance with a high antioxidant capacity. This is the final product of the adenosinergic pathway and is a biomarker of PD progression. McFarland and colleagues demonstrated that urate levels in cortical and striatal tissues tended to be lower in $\mathrm{PD}$ and $\mathrm{AD}$ than in controls (Cipriani et al., 2010; McFarland et al., 2013). These data strongly suggest that the appearance and development of PD may be related to low urate levels (McFarland et al., 2013; Schwarzschild et al., 2014; Chen et al., 2018). This may be due to the oxidation of dopaminergic cells and other markers in the nigrostriatal region of PD (Church and Ward, 1994; Cipriani et al., 2010). In the SURE-PD (safety urate elevation study - Parkinson disease) clinical trial with a 24-month follow-up, it was demonstrated that the elevation of urate (with serum values between 6 and $8 \mathrm{mg} / \mathrm{dL}$ ) induced by the administration of inosine was safe. It provides a slower progression on the UPDRS scale, which assesses PD signs and symptoms (Schwarzschild et al., 2014). This effect is attributed to the antioxidant capacity of uric acid, given the relationship between oxidative stress and neuronal death in dopaminergic cells (Cipriani et al., 2014; Schwarzschild et al., 2014; Crotty et al., 2017; Paganoni and Schwarzschild, 2017). This study also demonstrated that these elevated urate levels are safe and do not induce urolithiasis, nephrolithiasis, or cardiovascular changes (Schwarzschild et al., 2014; Chen et al., 2018).

The SURE-PD study also demonstrated that inosine led to a significantly higher increase in urate levels in women than that in men, although women started at a lower baseline level (Schwarzschild et al., 2019). In cerebrospinal fluid (CSF), inosine alone was able to increase urate levels in women. The sex of the patients may have been a factor influencing these distinct changes, as inosine induced a more significant reduction in the UPDRS score in women than that in men, suggesting that high urate levels should be more effective in delaying the progression of PD in women than in men (Schwarzschild et al., 2019). In the SURE-PD study, it was found that oral administration of inosine to patients was able to increase the concentration of ferric reducing antioxidant power (FRAP), a measure of antioxidant capacity, in serum levels but not in CSF. FRAP enhancement is inversely proportional to the rate of clinical decline in patients (Bhattacharyya et al., 2016). In another clinical study in an Asian population, administration of inosine for 1 year did not induce any significant side effects, but there were no clinical improvements on the UPDRS scale (Iwaki et al., 2017).

In a cellular model of PD induced by the addition of $\mathrm{H}_{2} \mathrm{O}_{2}$ to a dopaminergic cells line, called MES 23.5, it was demonstrated that inosine might be a potential treatment for producing antiinflammatory, trophic, and antitoxic effects in vitro. However, these neuroprotective effects of inosine were found only when the MES 23.5 cells were cultured together with a low density of cortical astrocytes, suggesting that this effect is dependent on the release of protective factors from these astrocytes (Cipriani et al., 2014). Another group of researchers evaluated the effect of inosine in an animal model of PD induced by rotenone. In this case, inosine imparted protective effects on protected behavioral, biochemical, and histological parameters. This study suggests that inosine reduced neuroinflammation and oxidative stress due to the suppression of ERK phosphorylation and the downregulation of adenosine $\mathrm{A}_{2 \mathrm{~A}}$ receptor expression (ElShamarka et al., 2020). In another animal model induced by MPTP, it was demonstrated that the use of an adenosine deaminase inhibitor (ADA), which is the enzyme that converts adenosine to inosine, has a neuroprotective effect. Adenosine $\mathrm{A}_{2 \mathrm{~A}}$ receptor antagonists also have similar effects.

Furthermore, MPTP has been shown to increase ADA activity to induce significantly higher inosine formation. On the other hand, inosine formation after MPTP can also be considered an attempt to reverse the neurodegenerative effects caused by this toxin (Huang et al., 2019). Taken together, these findings confirm the involvement of the adenosinergic pathway in an animal model of PD. 
Taken together, even though the inosine results on $\mathrm{PD}$ are quite encouraging in the SURE-PD clinical trial and its results corroborate with some preclinical studies, we can conclude that this nucleoside should be more studied by more research groups in both animals and humans to test its real potential to treat this neurodegenerative disease.

\section{INOSINE AND SCHIZOPHRENIA}

Several studies have shown that the adenosinergic system may be altered in schizophrenia (SZ), primarily through the effects of adenosine and nucleotide receptors on dopaminergic and glutamatergic signaling, and as deficiency of inosine is associated with SZ (Malewska-Kasprzak et al., 2019). Moreover, many SZ features may be attributed to purinergic signaling dysfunction, called "purinergic hypotheses," considering that SZ patients present a persistently decreased adenosinergic activity (Lara et al., 2006). Furthermore, adenosine $A_{2 A}$ receptor knockout mice show motor disturbances, social and cognitive alterations, and lateral ventricle enlargement related to psychotic symptoms (Moscoso-Castro et al., 2016). Some studies indicate that inosine is involved in SZ development, but the scarcity of more robust results is still evident.

Using generalized singular value decomposition (GSVD), a new algorithm for metabolomic data analysis, Xiao et al. (2011) assessed metabolomic data from the prefrontal cortex (PFC) of $N$-methyl-D-aspartic acid (NMDA) receptor antagonist phencyclidine (PCP)-treated rats, a translational model of SZ. This approach identified a significant disruption in purinergic reactions, denoted by a substantial increase in adenylosuccinate synthase (ADSS), which is responsible for converting IMP to adenylosuccinate, causing imbalance, an increase in inosine levels and downstream metabolites of other enzymes (e.g., IMP, hypoxanthine, and xanthine).

Stress plays a relevant role in the pathogenesis of SZ. In a refined design, Cai et al. (2017) investigated stress-related metabolic pathways in chronic unpredictable mild stress (CUMS) (stress axis activation), long-term dexamethasone exposure (LTDE) (stress axis activation) rat models, and animals treated with clozapine (CLO), risperidone (RIS), and aripiprazole (ARI). These animals showed an imbalance in the bioenergetic pathways responsible for ATP replenishment in the brain. Compared to controls, inosine levels in the PFC and hippocampus were decreased in the CUMS group and increased in the LTDE and CLO groups. Hypoxanthine and uric acid followed the same pattern in the CUMS and LTDE groups. These findings support the rationale that mitochondrial dysfunction and purine metabolism are closely related to stress-induced pathology. Then, the production of uric acid, a scavenger of reactive oxygen species, is reduced when the adenosine pathway is disturbed because inosine and hypoxanthine are its substrates.

Serum adenosine deaminase (ADA) activity, an enzyme that catalyzes adenosine to inosine, is abnormally high in male SZ patients treated with either typical antipsychotics or CLO, even after adjusting for confounding factors (Brunstein et al., 2007). Conversely, increased gene expression levels of ADA and reduced levels of adenosine transporter, equilibrative nucleoside transporter 1 (ENT1), were observed in enriched populations of pyramidal neurons post-mortem sections from the dorsolateral prefrontal cortex (DLPFC) of patients with SZ. However, no changes in inosine levels were detected in DLPFC tissue homogenates in SZ versus controls (O’Donovan et al., 2018).

Adenosine may play a protective role in SZ, particularly through its antipsychotic effects (Ossowska et al., 2020). Lower ADA activity is linked to a functional variant in the ADA gene $\left(A D A 1^{*} 2\right)$, which would raise adenosine levels and, by extension, inosine levels (Battistuzzi et al., 1981). As a result, this polymorphism may protect against SZ development. Indeed, this variant presents a lower frequency in male individuals with SZ in a Brazilian cohort. Patients carrying the G/A genotype demonstrate a decrease in about $20-30 \%$ of the ADA's enzymatic activity (Dutra et al., 2010).

Inosine may also act as guanosine in cellular processes. Inosine is a modified adenosine in RNA, generated by hydrolytic deamination of adenosine and catalyzed by adenosine deaminase acting RNA (ADAR), called A-to-I RNA editing. Deregulation in this biological process affects pathological conditions (Okada et al., 2015). Genome-wide association studies have pointed out that the etiopathogenesis of neuropsychiatric disorders, such as SZ, is related to the host genetic background (Barešić et al., 2019). Searching for possible deregulation of A-to-I RNA editing in frozen human post-mortem brain samples by Silberg et al. (2011), revealed that $\mathrm{SZ}$ and suicide victims presented an increased $A D A R$ (e.g., $A D A R 2, A D A R 3$, and $A D R B 1$ ) gene variants that codify enzyme isoforms transcripts with decreased catalytic activity. Additionally, the ADARB1 rs9983925 single nucleotide variant (SNV) has been associated with suicide attempts in Serbian psychiatric patients exposed to traumatic childhood experiences (Karanović et al., 2015).

To the best of our knowledge, no clinical or experimental study has been conducted to evaluate the biological role of inosine in SZ. We have demonstrated that inosine may act through adenosine $\mathrm{A}_{1}, \mathrm{~A}_{2} \mathrm{~A}$, and $\mathrm{A}_{2 \mathrm{~A}}$ receptors (Lapa et al., 2013; Nascimento et al., 2015). The mitogen-activated protein kinase (MAPK), which regulates inflammation, participates in downstream signaling (Welihinda et al., 2016). Considering that inosine negatively regulates oxidative stress (Ruhal and Dhingra, 2018) and neuroinflammation (Junqueira et al., 2017), all crucial components in the pathophysiological course of SZ, this nucleoside could present relevant positive implications in the treatment of SZ.

\section{INOSINE AND EPILEPSY}

The effects of inosine on epilepsy have been studied since the 1980s. Early studies on this topic indicated that inosine could interact with benzodiazepine receptors, explaining its antiepileptic effects in several animal models of epilepsy, especially tonic-clonic seizures. Recently, a group of studies has suggested that inosine has a pro-epileptic effect, especially in a rodent absence model of human absence epilepsy. Moreover, some studies have demonstrated that inosine brain levels are 
increased in animal models of epilepsy. This section provides an overview of these findings.

There are many different types of seizures; generalized seizures, that involve large bilateral brain areas, comprehend one of the three main categories of epilepsy (Marshall et al., 2021). Generalized seizures can be presented as tonic-clonic seizures or as absence epilepsy. Tonic-clonic seizures are the most common seizures associated with epilepsy. During the tonic phase, there is loss of consciousness and the body is entirely rigid, and in the clonic phase, there is uncontrolled jerking of the limbs and possible difficulty breathing (Marshall et al., 2021). Absence epilepsy is a brief non-convulsive seizure associated with sudden abruptness in consciousness (Jafarian et al., 2020).

Some studies have indicated that inosine may have antiepileptic effects in different animal models of epilepsy. This evidence emerged in the early 1980s when inosine was identified as one of the main compounds of bovine brain extracts responsible for competitively inhibiting the binding of $\left[{ }^{3} \mathrm{H}\right]$-diazepam to rat synaptosomal brain membranes (Asano and Spector, 1979). Subsequently, Skolnick et al. (1979) demonstrated that intracerebroventricular (i.c.v.) administration of inosine induced a dose-dependent and time-dependent increase in the latency period to the onset of clonic-tonic convulsions induced by pentylenetetrazol (PTZ). Recently, Ganzella et al. (2011) also demonstrated that i.c.v. administration of inosine protected against quinolinic acid-induced seizures in a time and dose-dependent manner, protecting around $60 \%$ of animals at the highest dose tested (400 nmol). Interestingly, intraperitoneal administration of flumazenil, a $\mathrm{GABA}_{\mathrm{A}}$ receptor antagonist, or caffeine, an adenosine receptor antagonist, did not change inosine protective effect against quinolinic acid-induced seizures (Ganzella et al., 2011). Considering these findings, inosine seems to exert a partial antagonism on PTZ seizures, which can be explained by its interaction with $\mathrm{GABA}_{\mathrm{A}}$ receptors. Moreover, inosine protects against quinolinic acid-induced seizures in a $\mathrm{GABA}_{\mathrm{A}}$ receptor-independent manner.

In another approach, i.c.v. administration of inosine in SHR mice $10 \mathrm{~min}$ prior to DL-kynurenine significantly reduced the number of mice with DL-kynurenine-induced clonic seizures (Lapin, 1981). Conversely, neither intraperitoneal nor i.c.v. inosine administration prevented seizures induced by PTZ in C57BL/6 or SHR mice (Lapin, 1981).

Systemic administration of inosine has also been shown to have anticonvulsant effects, as demonstrated by pre-treatment with inosine $(500-1000 \mathrm{mg} / \mathrm{kg})$, which promoted an increase in the latency of tonic-clonic seizures induced by caffeine in mice and reduced the percentage of animals experiencing seizures (Marangos et al., 1981). In addition, intraperitoneal inosine $(1000 \mathrm{mg} / \mathrm{kg})$ reduced the number of mice displaying clonic convulsions and prolonged the latency of clonic convulsions induced by DL-kynurenine C57BL/6 and BALB/c mice (Lapin, 1981). Lewin and Bleck (1985) used BALB/c mice to demonstrate that inosine increased the epileptic dose threshold for PTZ, bicuculline, or picrotoxin and prolonged the time for the first myoclonic contraction induced by these convulsant agents. Interestingly, after subcutaneous administration of the highest dose $(1000 \mathrm{mg} / \mathrm{kg})$, an inosine brain concentration of $14.4 \mu \mathrm{M}$ was reached, suggesting that micromolar concentrations of inosine in the brain are associated with its antiepileptic effects (Lewin and Bleck, 1985).

Recently, Brillatz et al. (2018) demonstrated that inosine also presents antiepileptic effects in a zebrafish epilepsy model with seizures induced by pentylenetetrazol. Interestingly, the authors demonstrated that inosine is the major component of the marine diatom Skeletonema marinoi, which also exhibited anticonvulsant effects in zebrafish with PTZ-induced epilepsy (Brillatz et al., 2018). Another research group has proposed a pro-epileptic activity for inosine. Kovács et al. (2015a,b) used Wistar Albino Glaxo/Rijswijk (WAG/Rij) rats, a genetically absent epileptic WAG/Rij rat model that spontaneously generates absence-like seizures. The absence-like seizures in WAG/Rij rats, especially those older than 3 months, can be evidenced in electroencephalographic recordings by bilateral synchronous and spontaneously occurring spike-wave discharges (SWDs) (Kovács et al., 2015a). It has been demonstrated that intraperitoneal inosine injection $(500$ or $1000 \mathrm{mg} / \mathrm{kg}$ ) significantly increased SWD in WAG/Rij rats. Furthermore, a combined injection of inosine (500 or $1000 \mathrm{mg} / \mathrm{kg}$ ) and LPS increased the SWD number and the total time of SWD to a more significant extent than LPS or inosine alone, suggesting that inosine potentiated LPS-induced SWD (Kovács et al., 2015b). Interestingly, muscimol (a GABAa receptor agonist)-induced increase in SWD number was potentiated by inosine $(500 \mathrm{mg} / \mathrm{kg})$ (Kovács et al., 2015b). Meanwhile, pre-treatment with bicuculline (a GABAa receptor antagonist) before intraperitoneal inosine administration $(500 \mathrm{mg} / \mathrm{kg})$ seems to prevent inosine-induced SWD (Kovács et al., 2015a). Taken together, these findings suggest that inosine induces absence-like seizures in WAG/Rij rats, and GABAa receptors could mediate inosine effects. In a different approach, Lakátos et al. (2018) demonstrated that the combined application of allopurinol (a xanthine oxidase inhibitor) and inosine significantly increased the SWD number when compared to allopurinol treatment or inosine treatment. These findings suggest that an increase in the endogenous levels of inosine due to the allopurinol inhibition of the xanthine oxidase enzyme may contribute to absencelike seizures in WAG/Rij rats, reinforcing the possible proepileptic effects of inosine in absence seizures (Lakátos et al., 2018).

Some studies have been designed to study inosine brain levels in animal models of epilepsy. Lewin and Bleck (1981) demonstrated that a sub-convulsive series of electroshocks in mice induces clonic movements and tonic extension of the hindlimbs. In this electroshock-induced seizure model, the authors showed that inosine brain levels increased significantly, reaching their maximal value at $5 \mathrm{~min}$ (for a $60-\mathrm{Hz}$ stimulus) and $1 \mathrm{~min}$ (for a $3-\mathrm{Hz}$ stimulus). Interestingly, phenytoin or phenobarbital administration markedly reduced the increase in inosine brain levels induced by electroshock (Lewin and Bleck, 1981). These results suggest that an early low increase in inosine brain levels following electroshock play a role in seizure generation and propagation. However, high concentrations of inosine after epileptic seizure recovery may contribute to seizure 
termination (Lewin and Bleck, 1981). In addition, Lehmann (1987) demonstrated that when folate was bilaterally injected into the amygdala of Albino rabbits, it induced limbic seizures and produced an increase in the hippocampal levels of inosine 10$130 \mathrm{~min}$ after injection. The authors suggested that increased inosine levels could be associated with ATP catabolism and indicate a minor perturbation of the cerebral energy state due to epileptic seizures induced by folate (Lehmann, 1987). In contrast, inosine levels in the cerebrospinal fluid (CSF) of patients with a rare disease characterized by progressive myoclonus epilepsy did not differ significantly from inosine levels in the CSF of control patients (Ohisalo et al., 1983). In an interesting case report, Ito et al. described a 4-year-old girl diagnosed with chronic mumps virus infection that presented with generalized tonicclonic seizures. It was demonstrated that the attacks subsided gradually after administering inosine pranobex (isoprinosine) $100 \mathrm{mg} / \mathrm{kg} /$ day (Ito et al., 1991). A marked decrease was observed in slow-wave activity by EEG after approximately 1 month of treatment with isoprinosine, and the patient became seizure-free 9 months after onset (Ito et al., 1991). However, the authors did not rule out the possibility of spontaneous remission (Ito et al., 1991). In addition, considering that inosine pranobex is a combination of inosine, acetamidobenzoic acid, and dimethylaminoisopropanol, it is impossible to conclude the actual contribution of inosine for the improvement of the epileptic seizures presented by the patient.

Considering these findings, there is an evident correlation between inosine and epilepsy. However, further studies are needed to clarify the nature of the aforementioned correlation, since some studies suggest a possible pro-epileptic effect, especially regarding absence seizures. In contrast, others have suggested an antiepileptic effect, mainly in tonicclonic episodes. In this sense, it would be interesting to evaluate inosine effects in animal models of chronic epilepsy and models used to identify drugs with efficacy against pharmacoresistant seizures. In parallel, identifying the mechanisms involved in the inosine effects in epilepsy is critical and can be performed using genetic, pharmacological, and in vitro approaches. Moreover, considering that some studies have identified increased inosine levels in the brains of animals subjected to epilepsy models, it would be essential to clarify whether these inosine levels contribute to the generation/propagation or termination of epileptic seizures. Together, these studies could extend the knowledge regarding inosine in epilepsy.

\section{INOSINE AND ANXIETY}

The interaction between inosine and anxiety is not entirely understood. Most studies dealing with this issue have been published in the late 1970s and early 1980s (Asano and Spector, 1979; Slater and Longman, 1979; Paul et al., 1980; Bold et al., 1985). Most of these studies used in vitro experiments and suggest a possible interaction between inosine and benzodiazepine receptors. However, few studies have evaluated the in vivo effects of inosine on anxiety. In this section, a review of these studies and suggestions for future directions will be provided to better understand the role of inosine in anxiety.

Identification of specific receptors in the brain that mediate the anxiolytic, muscle relaxation, and hypnotic effects of diazepam led to the hypothesis that an endogenous ligand for benzodiazepine receptors must also exist in the brain. In this context, Asano and Spector (1979) identified inosine present in bovine brain crude extracts as an endogenous competitive inhibitor of $\left[{ }^{3} \mathrm{H}\right]$ diazepam-binding benzodiazepine receptors. Inosine inhibited the binding of about $50 \%$ of $\left[{ }^{3} \mathrm{H}\right]$ diazepam at a concentration of $1.5 \mathrm{mM}$ to the benzodiazepine receptor in the rat brain (Asano and Spector, 1979). Regarding tissue specificity, the authors demonstrated that inosine had a much lower affinity for benzodiazepine receptors in peripheral tissues, such as the kidney and liver, than for those in the brain (Asano and Spector, 1979). Similar results were found previously (Paul et al., 1980) and later (Skolnick et al., 1978), providing evidence that inosine is a compound from brain extracts that competitively inhibits $\left[{ }^{3} \mathrm{H}\right]$ diazepam and $\left[{ }^{3} \mathrm{H}\right]$ flunitrazepam (Yarom et al., 1998) binding to the synaptosomal membrane. In addition, inosine inhibited neuronal excitability by increasing membrane conductance in cultured spinal neurons, an effect that was blocked by flurazepam (MacDonald et al., 1979). Together, these findings suggest that inosine could play a neuromodulatory role, mimicking or antagonizing the pharmacological effects of benzodiazepines. However, functional studies such as patch clamp studies or ion flux studies in cells transfected with the benzodiazepine receptors should have been conducted to clarify if inosine acts as an antagonist, agonist or even an inverse agonist of benzodiazepine receptors.

Interestingly, Slater and Longman (1979) used an in vivo method to detect drugs with GABA-mimetic properties. In this study, diazepam was injected striatally into the globus pallidus and a highly significant slowing of the head-turn, a behavior that can be modulated by GABA agonists or antagonists, was observed. This behavior was used to demonstrate the in vivo GABA-mimetic properties of benzodiazepines (Crossman et al., $1977,1979)$. Intrapallidal injection of inosine $(10 \mu \mathrm{g})$ had no significant effect on the head turn (Slater and Longman, 1979). However, when injected either before or together with diazepam, inosine completely prevented diazepam-induced head-turn slowing (Slater and Longman, 1979). These results suggest that inosine has no GABA-mimetic or benzodiazepinelike properties when tested with the head-turn model.

In contrast, inosine seems to interact with benzodiazepine receptors and can antagonize diazepam actions in the globus pallidus (Slater and Longman, 1979). These findings suggest that inosine could have an anxiogenic effect by antagonizing the actions of diazepam. In this context, Bold et al. (1985) demonstrated that inosine inhibited $\left[{ }^{3} \mathrm{H}\right]$-flunitrazepam binding to the benzodiazepine receptor in rat cerebellar cell membranes, with an $\mathrm{IC}_{50}$ value of $8 \mathrm{mM}$ and a low affinity for the receptor. Moreover, the same study used the social interaction test in rats, which has been proposed as a valid test for measuring anxiety. In this test, inosine did not increase social interaction in a manner comparable to that of benzodiazepines (Bold et al., 1985), indicating that inosine did not present an anxiolytic 
effect in the social interaction test. The authors did not evaluate whether inosine was able to reduce social interactions. It was also not assessed if inosine was able to inhibit the benzodiazepineinduced increase in social interaction. Thus, no conclusion could be drawn regarding the possible anxiogenic effects of inosine. Crawley et al. (1981) used an apparatus that records the number of transitions made by a mouse between an illuminated open-field compartment and a dark enclosed compartment. Benzodiazepine administration prior to the test significantly increased the number of such transitions and could be inferred to be related to the occurrence of an antianxiety effect.

Interestingly, inosine at doses ranging from 10 to $300 \mathrm{mg} / \mathrm{kg}$ (below the sedative range, $500-1000 \mathrm{mg} / \mathrm{kg}$ ) reversed the diazepam-induced increase in the number of transitions between light and dark compartments, suggesting that inosine can antagonize the anxiety-reducing actions of benzodiazepines (Crawley et al., 1981). In corroborating this finding, Wagner and Katz (1983) demonstrated that synthetic purines such as $2^{\prime}$ deoxyinosine and 7-methylinosine, that bind to benzodiazepine receptor, are structurally similar to inosine and seem to present a dose-related anxiogenic effect in Sprague-Dawley rats (Wagner and Katz, 1983). These results reinforce the findings, suggesting that endogenous inosine shows anxiogenic activity due to its interaction with benzodiazepine receptors.

In contrast to most of the findings that suggest a possible anxiogenic effect of inosine, Okuyama et al. (1998) demonstrated that inosine (10-60 mg/kg) administered subcutaneously to male ddY mice (an outbred mouse strain derived from a mouse colony at the Institute of Infectious Diseases of Tokyo University) Yamazaki et al. (2012) presented an anxiolytic-like effect in the Vogel-type anti-conflict test. Interestingly, in this study, inosine and other purines such as adenosine, AMP, c-AMP, and adenine have been isolated from the fruit of Euphoria longana (Longan Arillus); however, only inosine and adenosine seemed to have an anxiolytic-like effect (Okuyama et al., 1998). The Vogel-type anticonflict test presents an excellent predictive value for classical anxiolytic drugs, such as benzodiazepines (Campos et al., 2013). However, the test also responds to non-anxiolytic drugs (Campos et al., 2013), producing false-positive results. It is important to mention that the potential antinociceptive properties of inosine (Nascimento et al., 2010, 2015; Macedo-Junior et al., 2013) could influence the result found by Okuyama et al. (1998), considering the Vogel test involves the response of mice to a noxious electrical stimulus employed as punishment.

According to the findings described here, inosine seems to interact with benzodiazepine receptors, as suggested by studies that used cell membrane binding assays. However, these findings are relatively old, dating back to the late 1970s and throughout the 1980s. Taking that into account, it is crucial to confirm whether inosine acts as a benzodiazepine receptor antagonist. In these sense, functional studies in cells transfected with benzodiazepine receptors and/or in primary cell cultures could not only ensure the interaction of inosine with benzodiazepine receptors but also in particular demonstrate whether this interaction would be able to modify GABA channels functioning in the cell activation/inhibition dynamics (e.g., using patch-clamp assays). Another critical point is to understand whether inosine can change the activity/expression/levels of enzymes, proteins, or second messengers related to the benzodiazepine receptor signaling pathway and whether these findings could be related to its anxiolytic or anxiogenic effects. In addition, the assessment of the anxiolytic or anxiogenic activity of inosine should be performed on animal models associated with the subjacent neurobiology and which meet the criteria of predictive, face, and construct validation. Together, these findings clarify the role of inosine in anxiety.

\section{INOSINE AND DEPRESSION}

Several studies have demonstrated a relationship between inosine and depression. These studies showed the effect of inosine treatment in different animal models of depression and paved the way to identify the mechanisms of inosine action in depression. Interestingly, clinical studies have shown that serum inosine levels are associated with major depressive disorders in humans. A review of these studies will be provided in this section, and future directions will be suggested to incorporate inosine in treatment regimens or as a diagnostic biomarker in depressive disorders.

In our database search, the study by Kaster et al. (2013) seems to be among the first to evaluate the possible antidepressant effect of inosine in animal models of depression. In this study, the authors first performed a dose-response curve for inosine in the force swim test (FST) and the tail suspension test (TST). The results demonstrated that inosine significantly reduced the depression behavior in both tests. Similarly, Gonçalves et al. (2017a) demonstrated that inosine given by intraperitoneal route presented antidepressant activity in the TST. Corroborating these findings, Yuan et al. (2018) demonstrated that inosine presented an antidepressant-like effect in the FST in rats. In an interesting approach, an inosine-supplemented diet and an inosine-supplemented tap water presented an antidepressantlike activity, preventing, respectively, chronic unpredictable stress and chronic social defeat stress-induced in set of depressionlike behavior in mice (Muto et al., 2014). In addition, inosine improves neuronal proliferation in the mouse brain and promotes neuronal viability and neurite outgrowth in cultured neocortical neurons (Muto et al., 2014).

Regarding action mechanisms related to inosine antidepressant effects, Kaster et al. (2013) demonstrated that both adenosine $\mathrm{A}_{1}$ receptor antagonist (DPCPX) and adenosine $\mathrm{A}_{2 \mathrm{~A}}$ receptor antagonist (ZM241385) were able to prevent inosine antidepressant-like effects. Moreover, activation of PKA, PI3K/Akt, ERK1/2, CaMKII and mTORC1 and the inhibition of GSK-3 $\beta$ and NMDA receptors seems to be involved in the inosine antidepressant-like effects in the TST (Gonçalves et al., 2017a,b). Furthermore, hippocampal CREB phosphorylation, MAPK phosphorylation and BDNF transcription increased $24 \mathrm{~h}$ after a single intraperitoneal administration of inosine (Muto et al., 2014; Gonçalves et al., 2017a). Similarly, Yuan et al. (2018) demonstrated that inosine (10 or $50 \mathrm{mg} / \mathrm{kg}$, i.p.) previously administered at $30 \mathrm{~min}, 6 \mathrm{~h}$, and $24 \mathrm{~h}$ in rats induced 
a significant increase in phosphorylated ERK and CREB in the rat hippocampus.

From a clinical point of view, it has been suggested that the plasma levels of inosine are significantly reduced in individuals (aged 20-71 years) with major depressive disorder (MDD) when compared with control non-depressive individuals (AliSisto et al., 2016). However, the authors did not observe any statistically significant difference in inosine plasma levels between the remitted and non-remitted groups (Ali-Sisto et al., 2016). On the other hand, Mocking et al. (2021) demonstrated that inosine plasma levels were decreased in both males and females with recurrent major depressive disorder in remission. Zhou et al. (2019) studied the potential biomarkers of depression in children and adolescents with MDD. The authors found that inosine plasma levels are reduced in children and adolescents diagnosed with MDD when compared to health controls. Interestingly, regression analyses suggest that inosine plasma levels are more pronounced in the plasma of boys and among individuals with more severe symptoms of depression (Zhou et al., 2019). Furthermore, inosine plasma levels were significantly higher in individuals treated with antidepressant drugs than in healthy individuals. These studies suggest that inosine could be used as a diagnostic biomarker in individuals with MDD, especially in children and adolescents.

The evidence presented here suggests that inosine induced an antidepressant-like effect in various animal models of depression. However, it is important to note that most studies that evaluated inosine effects in animal models meet only the predictive validity criterion, such as FST and TST. In this sense, it would be essential to extend the test with inosine to animal models that also meet construct and face validities to evaluate its effect on the molecular and biochemical CNS alterations present in depression and classic depression symptoms like anhedonia. It would also be interesting to assess whether inosine increases serotonin/norepinephrine levels in the CNS in animal models of depression. Together, the investigation of these points could confirm, clarify, and extend the role of inosine in depression.

\section{INOSINE AND NEURAL REGENERATION}

The therapeutic effects of inosine, which regulates neuron activity, have been described in literature by several research groups. In the last four decades, studies have demonstrated that inosine can be released by cultured neuronal cells, modulate the neurotransmitter release, and activate intracellular signaling pathways that regulate the expression of multiple genes involved in axon outgrowth in vitro and in vivo. One of the first studies to show that inosine can modulate neuronal activity in vitro in adrenergic neurons has been the study by Zurn and Do (1988). The involvement of inosine in other modulatory events, including the growth and regeneration of neuronal connections, was investigated in cultured neural goldfish retinal ganglion cells and rat retinal ganglion cells (Benowitz et al., 1998; Petrausch et al., 2000). These studies have described inosine-stimulating axonal outgrowth through an intracellular mechanism that activates protein kinase-N, GAP-43, protein T alpha-1 tubulin, and L1, a cell adhesion molecule (Benowitz et al., 1998; Petrausch et al., 2000; Cook et al., 2004), mimicking at least one aspect of the molecular changes that underlie axonal regeneration in vivo.

These results have led researchers to perform confirmatory in vivo studies using animal models, including sciatic nerve injury (Hadlock et al., 1999; Cardoso et al., 2019), controlled cortical impaction (CCI) injury (Smith et al., 2007), closed head injury (Dachir et al., 2014), spinal cord injury (SCI) (Bohnert et al., 2007; Kim et al., 2013; Chung et al., 2015), and ischemic stroke (Chen et al., 2002; Zai et al., 2009, 2011; Benowitz and Carmichael, 2010). In the first published studies investigating the pharmacological effects of inosine, inosine was administered directly into the CNS using osmotic minipumps. The results obtained from these studies corroborate previous in vitro data. It has been demonstrated that inosine can stimulate undamaged neurons to extend collateral branches that grow into areas of the brainstem and spinal cord that lose their normal innervation due to injury when administered alone (Hadlock et al., 1999) or together with oscillating field stimulation (OFS) treatment (Bohnert et al., 2007). In addition, inosine combined with NEP140 , a potent antagonist of the Nogo receptor (the receptor of Nogo-A, a myelin-associated glycoprotein considered to be an inhibitor of neurite growth), doubled the number of axon branches extending from neurons in the intact hemisphere and induced the growth of bouton-like structures in the gray matter into the denervated side of the spinal cord (Zai et al., 2011).

Kim et al. (2013) also demonstrated promising effects of inosine administration on neuron outgrowth. In 2013, inosine was administered intravenously, showing that systemic administration induces axon sprouting in the CNS and increasing serotonergic input to the lumbar spinal cord, indicating that inosine can cross the blood-brain barrier. Thus, in subsequent studies, inosine effects were investigated systemically by intraperitoneal, intravenous, and oral routes in several animal models (Kim et al., 2013; Dachir et al., 2014; Chung et al., 2015; Moore et al., 2016; Cardoso et al., 2019). In these studies, inosine reduced the loss of urinary tract function (Chung et al., 2015), decreased the neurological severity score, and improved motor function (Dachir et al., 2014; Cardoso et al., 2019). All these effects are related to the induction of axon regeneration. Interestingly, when inosine is administered daily via the oral route $(500 \mathrm{mg} / \mathrm{kg})$ mixed in flavored yogurt, it induces a more remarkable recovery in terms of a return to standard grasp patterns (finger-thumb pinch) in a cortical injury model (Moore et al., 2016).

Evidence has indicated that the motor improvement observed after inosine treatment in vivo was directly related to an increase in the expression of growth-associated membrane phosphoprotein GAP- 43 in neural cells, suggesting that inosine may act similarly in vivo and in vitro, inducing a program of gene expression that enables axon regeneration. Another protein, $\mathrm{Mst} 3 \mathrm{~b}$, is related to the inosine mechanism in vitro, and is classified as a purine-sensitive protein kinase that plays a crucial role in axon outgrowth (Irwin et al., 2006).

In addition to a study that revealed a purine-sensitive protein, two exciting studies using an animal model of ischemic stroke and gene microarray analysis have demonstrated that inosine can 
affect gene expression in the CNS. The genes that are selectively upregulated by inosine include those encoding tissue inhibitors of metalloproteinase (timp1), metallothionein, galectin 3, and complement cascade proteins (Zai et al., 2009). Moreover, genes involved in cell signaling, cell morphology, cell maintenance, assembly and organization, DNA replication, recombination and repair, and nervous system development and function could be upregulated. The authors suggest that chromatin remodeling and genome-wide transcriptional changes may depend on Mst3b activation, a hypothesis that requires further testing (Zai et al., 2011). The data demonstrating inosine effects activating specific proteins and modulating gene transcription are quite promising and may be linked to the enhanced ability of neurons to modify synaptic relationships or promote axon branching. This induction of neural plasticity and axonal sprouting is the basis for behavioral improvement.

Besides the mechanisms involved in inosine-induced plasticity that have been investigated at the molecular level, the contribution of adenosine $\mathrm{P} 1$ receptor-signaling pathways to neuronal outgrowth needs to be addressed, since its role in inflammation, immunity, pain, and CNS pathologies has been reported in the literature. The inosine-induced neuronal outgrowth observed in multiple animal models of neurological injury, its clinical safety in humans, and the feasibility of administration, including the oral route, indicates inosine as an excellent candidate for clinical trials of treatment regimens of patients with CNS injuries.

\section{FUTURE ADVANCES AND PERSPECTIVES}

A few decades ago, inosine was considered an inert molecule resulting from the degradation of adenosine. In this review,

\section{REFERENCES}

Adebiyi, M. G., Manalo, J., Kellems, R. E., and Xia, Y. (2019). Differential role of adenosine signaling cascade in acute and chronic pain. Neurosci. Lett. 712:134483. doi: 10.1016/j.neulet.2019.134483

Ali-Sisto, T., Tolmunen, T., Toffol, E., Viinamäki, H., Mäntyselkä, P., ValkonenKorhonen, M., et al. (2016). Purine metabolism is dysregulated in patients with major depressive disorder. Psychoneuroendocrinology 70, 25-32. doi: 10.1016/j. psyneuen.2016.04.017

Al-Shamiri, S. A., Hasan, N. A., Frankul, W. M., and Al-Hamdi, A. T. (2009). Purines and oxypurines in myocardial ischemia. Saudi Med. J. 30, 257-266.

Ameta, K., Gupta, A., Ameta, D., Sethi, R., Kumar, D., Ahmad, I., et al. (2016). $1 \mathrm{H}$ NMR-derived metabolomics of filtered serum of myocardial ischemia in unstable angina patients. Clin. Chim. Acta 456, 56-62. doi: 10.1016/j.cca.2016. 02.020

Asano, T., and Spector, S. (1979). Identification of inosine and hypoxanthine as endogenous ligands for the brain benzodiazepine-binding sites. Proc. Natl. Acad. Sci. U.S.A. 76, 977-981. doi: 10.1073/pnas.76.2.977

Barešić, A., Nash, A. J., Dahoun, T., Howes, O., and Lenhard, B. (2019) Understanding the genetics of neuropsychiatric disorders: the potential role of genomic regulatory blocks. Mol. Psychiatry 25, 6-18. doi: 10.1038/s41380-0190518-x

Battistuzzi, G., Ludicone, P., Santolamazza, P., and Petrucci, R. (1981). Activity of adenosine deaminase allelic forms in intact erythrocytes and in lymphocytes. Ann. Hum. Genet. 45, 15-19. doi: 10.1111/j.1469-1809.1981.tb00301.x we discuss the current knowledge and describe the myriad scientific evidence that highlight the critical effects of inosine on the central nervous system. Evidence of inosine-binding sites, mainly adenosine receptors, supports an increment of inosine research in the future investigating its physiological role in the CNS disorders and its potential for the development of new therapeutic approaches to treat neurological and psychiatric disorders (see Figure 1). We believe that inosine is a great molecule that has been neglected until now and that it is able to treat several physiological disturbs safely. Therefore, we hope that this review can support and promote a path for further investigation of the benefits of inosine through preclinical (in silico, in vitro, and in vivo) and clinical studies.

\section{AUTHOR CONTRIBUTIONS}

FN planned and was responsible for the coordination and overall supervision of the study. All the authors contributed equally to writing and editing the manuscript and approved the final manuscript.

\section{ACKNOWLEDGMENTS}

The present review is dedicated to the memory of AS who passed away in July 2021. AS founded the Laboratory of Neurobiology of Pain and Inflammation in Florianópolis, where three authors of this work have got their Ph.D. degrees studying inosine. He was a big science enthusiast and a friend to all who knew him. He had a personal passion for the adenosinergic system, and he spent many years and efforts seeking to understand its fundamental principles. To this great scientist, master, and friend, our deepest gratitude.

Benowitz, L. I., and Carmichael, S. T. (2010). Promoting axonal rewiring to improve outcome after stroke. Neurobiol Dis. 37, 259-266. doi: 10.1016/j.nbd. 2009.11.009

Benowitz, L. I., Jing, Y., Tabibiazar, R., Jo, S. A., Petrausch, B., Stuermer, C. A., et al. (1998). Axon outgrowth is regulated by an intracellular purine-sensitive mechanism in retinal ganglion cells. J. Biol. Chem. 273, 29626-29634. doi: 10.1074/jbc.273.45.29626

Bhattacharyya, S., Bakshi, R., Logan, R., Ascherio, A., Macklin, E. A., and Schwarzschild, M. A. (2016). Oral inosine persistently elevates plasma antioxidant capacity in Parkinson's disease. Mov. Disord. 31, 417-421. doi: $10.1002 / \mathrm{mds} .26483$

Bohnert, D. M., Purvines, S., Shapiro, S., and Borgens, R. B. (2007). Simultaneous application of two neurotrophic factors after spinal cord injury. J. Neurotrauma 24, 846-863. doi: 10.1089/neu.2006.0101

Bold, J. M., Gardner, C. R., and Walker, R. J. (1985). Central effects of nicotinamide and inosine which are not mediated through benzodiazepine receptors. Br. J. Pharmacol. 84, 689-696. doi: 10.1111/j.1476-5381.1985.tb16151.x

Brillatz, T., Lauritano, C., Jacmin, M., Khamma, S., Marcourt, L., Righi, D., et al. (2018). Zebrafish-based identification of the antiseizure nucleoside inosine from the marine diatom Skeletonema marinoi. PLoS One 13:e0196195. doi: 10.1371/journal.pone.0196195

Brunstein, M. G., Silveira, E. M. Jr., Chaves, L. S., Machado, H., Schenkel, O., Belmonte-de-Abreu, P., et al. (2007). Increased serum adenosine deaminase activity in schizophrenic receiving antipsychotic treatment. Neurosci. Lett. 414, 61-64. doi: 10.1016/j.neulet.2006.11.071 
Burnstock, G. (2006). Purinergic signalling. Br. J. Pharmacol. 147, S172-S181. doi: 10.3389/fphar.2017.00661

Burnstock, G. (2007). Physiology and pathophysiology of purinergic neurotransmission. Physiol. Rev. 87, 659-797. doi: 10.1152/physrev.00043.2006

Burnstock, G. (2020). "Introduction to purinergic signalling in the brain," in Glioma signaling, ed. J. Baranska (Switzerland: Springer), 1.

Cai, H. L., Jiang, P., Tan, Q. Y., Dang, R. L., Tang, M. M., Xue, Y., et al. (2017). Therapeutic efficacy of atypical antipsychotic drugs by targeting multiple stressrelated metabolic pathways. Transl. Psychiatry 7:e1130. doi: 10.1038/tp.2017. 94

Campos, A. C., Fogaça, M. V., Aguiar, D. C., and Guimarães, F. S. (2013). Animal models of anxiety disorders and stress. Animal models of anxiety disorders and stress. Braz. J. Psychiatry 35, S101-S111. doi: 10.1590/1516-4446-20131139

Cardoso, F. S. S., Cardoso, R., Ramalho, B. S., Taboada, T. B., Nogueira, A. C. S., Martinez, A. M. B., et al. (2019). Inosine accelerates the regeneration and anticipates the functional recovery after sciatic nerve crush injury in mice. Neuroscience 15, 206-215. doi: 10.1016/j.neuroscience.2019.0 9.023

Chen, P., Goldberg, D. E., Kolb, B., Lanser, M., and Benowitz, L. I. (2002). Inosine induces axonal rewiring and improves behavioral outcome after stroke. Proc. Natl. Acad. Sci. U.S.A. 99, 9031-9036. doi: 10.1073/pnas.13207 6299

Chen, X., Umeh, C. C., Tainsh, R. E., Feng, D. D., Maguire, M., Zuo, F., et al. (2018). Dissociation between urate and blood pressure in mice and in peopel with early Parkinson's disease. EBioMedicine 37, 259-268. doi: 10.1016/j.ebiom.2018.10. 039

Chung, Y. G., Seth, A., Doyle, C., Franck, D., Kim, D., and Cristofaro, V. (2015). Inosine improves neurogenic detrusor overactivity following spinal cord injury. PLoS One 10:e0141492. doi: 10.1371/journal.pone.014 1492

Church, W. H., and Ward, V. L. (1994). Uric acid is reduced in the substantia nigra in Parkinson's disease: effect on dopamine oxidation. Brain Res. Bull. 33, 419-425. doi: 10.1016/0361-9230(94)90285-2

Cipriani, S., Bakshi, R., and Schwarzschild, M. A. (2014). Protection by inosine in a cellular model of Parkinson's disease. Neuroscience 22, 242-249. doi: 10.1016/ j.neuroscience.2014.05.038

Cipriani, S., Chen, X., and Schwarzschild, M. A. (2010). Urate: a novel biomarker of Parkinson's disease risk, diagnosis and prognosis. Biomark. Med. 4, 701-712. doi: $10.2217 / \mathrm{bmm} .10 .94$

Cook, D. J., Kulbatski, I., and Tator, C. H. (2004). Inosine reverses the inhibitory effects of the L-type Ca2pchannel antagonist, DM-BODIPY-dihydropyridine, on neuritogenesis in an in vitro rat superior cervical ganglia axotomy model. Neurosci. Lett. 358, 75-78. doi: 10.1016/j.neulet.2003.12.113

Crawley, J. N., Marangos, P. J., Paul, S. M., Skolnick, P., and Goodwin, F. K. (1981). Interaction between purine and benzodiazepine: inosine reverses diazepaminduced stimulation of mouse exploratory behavior. Science 211, 725-727. doi: $10.1126 /$ science. 6256859

Crossman, A. R., Lee, L. A., Longman, D. A., and Slater, P. (1979). Effects of benzodiazepines and barbiturates in a GABA-dependent animal model: interactions with muscimol in the Globus pallidus. Br. J. Pharmacol. 66, 493P$494 \mathrm{P}$.

Crossman, A. R., Lee, L. A., and Slater, P. (1977). Effects of manipulating pallidal and nigral GABA on striatally-mediated head-turning in the rat. $\mathrm{Br}$. J. Pharmacol. 61:483.

Crotty, G. F., Ascherio, A., and Schwarzschild, M. A. (2017). Targeting urate to reduce oxidative stress in Parkinson disease. Exp. Neurol. 298, 210-224. doi: 10.1016/j.expneurol.2017.06.017

Dachir, S., Shabashov, D., Trembovler, V., Alexandrovich, A. G., Benowitz, L. I., and Shohami, E. (2014). Inosine improves functional recovery after experimental traumatic brain injury. Brain Res. 1555, 78-88. doi: 10.1016/j.brainres.2014.01. 044

de Oliveira, E. D., Schallenberger, C., Böhmer, A. E., Hansel, G., Fagundes, A. C., Milman, M., et al. (2016). Mechanisms involved in the antinociception induced by spinal administration of inosine or guanine in mice. Eur. J. Pharmacol. 772, 71-82. doi: 10.1016/j.ejphar.2015.12.034
Doyle, C., Cristofaro, V., Sack, B. S., Lukianov, S. N., Schafer, M., Chung, Y. G., et al. (2017). Inosine attenuates spontaneous activity in the rat neurogenic bladder through an A2B pathway. Sci. Rep. 7:44416. doi: 10.1038/srep4 4416

Doyle, C., Cristofaro, V., Sullivan, M. P., and Adam, R. M. (2018). Inosine - a multifunctional treatment for complications of neurologic injury. Cell. Physiol. Biochem. 49, 2293-2303. doi: 10.1159/000493831

Dutra, G. P., Ottoni, G. L., Lara, D. R., and Bogo, M. R. (2010). Lower frequency of the low activity adenosine deaminase allelic variant $\left(\mathrm{ADAl}^{*} 2\right)$ in schizophrenic patients. Braz J Psychiatry. 32, 275-278. doi: 10.1590/s151644462010005000003

El-Shamarka, M. E. A., Kozman, M. R., and Messiha, B. A. S. (2020). The protective effect of inosine against rotenone-induced Parkinson's disease in mice: role of oxido-nitrosative stress, ERK phosphorylation, and A2AR expression. Naunyn Schmiedebergs Arch. Pharmacol. 393, 1041-1053. doi: 10.1007/s00210-01901804-1

Eltzschig, H. K. (2009). Adenosine: an old drug newly discovered. Anesthesiology 111, 904-915. doi: 10.1097/ALN.0b013e3181b060f2

Eltzschig, H. K., Faigle, M., Knapp, S., Karhausen, J., Ibla, J., and Rosenberger, P. (2006). Endothelial catabolism of extracellular adenosine during hypoxia: the role of surface adenosine deaminase and CD26. Blood 108, 1602-1610. doi: 10.1182/blood-2006-02-001016

Fais, A., Cacace, E., Corda, M., Era, B., Peri, M., and Utzeri, S. (2013). Purine metabolites in fibromyalgia syndrome. Clin. Biochem. 46, 37-39. doi: 10.1016/j. clinbiochem.2012.09.009

Farthing, D. E., Sica, D., Hindle, M., Edinboro, L., Xi, L., Gehr, T. W., et al. (2011). A rapid and simple chemiluminescence method for screening levels of inosine and hypoxanthine in non-traumatic chest pain patients. Luminescence 26, 65-75. doi: 10.1002/bio.1187

Farthing, D., Sica, D., Gehr, T., Wilson, B., Fakhry, I., Larus, T., et al. (2007). An HPLC method for determination of inosine and hypoxanthine in human plasma from healthy volunteers and patients presenting with potential acute cardiac ischemia. J. Chromatogr. B Analyt. Technol. Biomed. Life Sci. 854, 158-164. doi: 10.1016/j.jchromb.2007.04.013

Farthing, D., Xi, L., Gehr, L., Sica, D., Larus, T., and Karnes, H. T. (2006). High-performance liquid chromatography (HPLC) determination of inosine, a potential biomarker for initial cardiac ischaemia, using isolated mouse hearts. Biomarkers 11, 449-459. doi: 10.1080/13547500600800074

Fredholm, B. B., IJzerman, A. P., Jacobson, K. A., Linden, J., and Muller, C. E. (2011). International Union of Basic and Clinical Pharmacology. LXXXI. Nomenclature and classification of adenosine receptors-an update. Pharmacol. Rev. 63, 1-34. doi: 10.1124/pr.110.003285

Ganzella, M., Faraco, R. B., Almeida, R. F., Fernandes, V. F., and Souza, D. O. (2011). Intracerebroventricular administration of inosine is anticonvulsant against quinolinic acid-induced seizures in mice: an effect independent of benzodiazepine and adenosine receptors. Pharmacol. Biochem. Behav. 100, 271-274. doi: 10.1016/j.pbb.2011.09.001

Garcia Soriano, F., Liaudet, L., Marton, A., Haskó, G., Batista Lorigados, C., Deitch, E. A., et al. (2001). Inosine improves gut permeability and vascular reactivity in endotoxic shock. Crit. Care Med. 29, 703-708. doi: 10.1097/00003246200104000-00001

Gomez, G., and Sitkovsky, M. V. (2003). Differential requirement for A2a and A3 adenosine receptors for the protective effect of inosine in vivo. Blood 102, 4472-4478. doi: 10.1182/blood-2002-11-3624

Gonçalves, F. M., Neis, V. B., Rieger, D. K., Lopes, M. W., Heinrich, I. A., Costa, A. P., et al. (2017a). Signaling pathways underlying the antidepressant-like effect of inosine in mice. Purinergic Signal. 13, 203-214. doi: 10.1007/s11302-0169551-2

Gonçalves, F. M., Neis, V. B., Rieger, D. K., Peres, T. V., Lopes, M. W., Heinrich, I. A., et al. (2017b). Glutamatergic system and mTOR-signaling pathway participate in the antidepressant-like effect of inosine in the tail suspension test. J. Neural Transm. (Vienna) 124, 1227-1237. doi: 10.1007/s00702-017-1 753-4

Gutierres, J. M., Carvalho, F. B., Schetinger, M. R., Marisco, P., Agostinho, P., Rodrigues, M., et al. (2014). Anthocyanins restore behavioral and biochemical changes caused by streptozotocin-induced sporadic dementia of Alzheimer's type. Life Sci. 96, 7-17. doi: 10.1016/j.lfs.2013.11.014 
Hadlock, T., Sundback, C., Koka, R., Hunter, D., Cheney, M., and Vacanti, J. (1999). A novel, biodegradable polymer conduit delivers neurotrophins and promotes nerve regeneration. Laryrigoscope 109, 1412-1416. doi: 10.1097/ 00005537-199909000-00010

Haskó, G., Kuhel, D. G., Németh, Z. H., Mabley, J. G., Stachelewitz, R. F., Virág, L., et al. (2000). Inosine inhibits inflammatory cytokine production by a posttranscriptional mechanism and protects against endotoxin-induced shock. J. Immunol. 164, 1013-1019. doi: 10.4049/jimmunol.164.2.1013

Haskó, G., Sitkovsky, M. V., and Szabó, C. (2004). Immunomodulatory and neuroprotective effects of inosine. Trends Pharmacol. Sci. 25, 152-157. doi: 10.1016/j.tips.2004.01.006

Hou, B., Xu, Z. W., Yang, C. W., Gao, Y., Zhao, S. F., and Zhang, C. G. (2007). Protective effects of inosine on mice subjeted to lethal total-body ionizing irradioation. J. Radiat. Res. 48, 57-62. doi: 10.1269/jrr.06067

Huang, W., Xu, Y., Zhang, Y., Zhang, P., Zhang, Q., Zhang, Z., et al. (2019). Metabolomics-driven identification of adenosine deaminase as therapeutic target in a mouse model of Parkinson's disease. J. Neurochem. 150, 282-295. doi: $10.1111 /$ jnc. 14774

Irwin, N., Li, Y.-M., O’Toole, J. E., and Benowitz, L. I. (2006). Mst3b, a purine sensitive Ste20-like protein kinase, regulates axon outgrowth. Proc. Natl. Acad. Sci. U.S.A. 103, 18320-18325. doi: 10.1073/pnas.0605135103

Ito, M., Go, T., Okuno, T., and Mikawa, H. (1991). Chronic mumps virus encephalitis. Pediatr. Neurol. 7, 467-470. doi: 10.1016/0887-8994(91)90033-h

Iwaki, H., Ando, R., Miyaue, N., Tada, S., Tsujii, T., Yabe, H., et al. (2017). One year safety and efficacy of inosine to increase the serum urate level for patients with Parkinson's disease in Japan. Neurol. Sci. 383, 75-78. doi: 10.1016/j.jns.2017.10. 030

Jafarian, M., Alipour, M. E., and Karimzadeh, F. (2020). Experimental Models of Absence Epilepsy. Basic Clin. Neurosci. 11, 715-726. doi: 10.32598/bcn.11.6.731. 1

Jin, X., Shepherd, R. K., Duling, B. R., and Linden, J. (1997). Inosine binds to A3 adenosine receptors and stimulates mast cell degranulation. J. Clin. Invest. 100, 2849-2857. doi: 10.1172/JCI119833

Junqueira, S. C., dos Santos Coelho, I., Lieberknecht, V., Cunha, M. P., Calixto, J. B., Rodrigues, A. L. S., et al. (2017). Inosine, an endogenous purine nucleoside, suppresses immune responses and protects mice from experimental autoimmune encephalomyelitis: a role for A2A adenosine receptor. Mol. Neurobiol. 54, 3271-3285. doi: 10.1007/s12035-016-9893-3

Karanović, J., Šviković, S., Pantović, M., Durica, S., Brajušković, G., Damjanović, A., et al. (2015). Joint effect of ADARB1 gene, HTR2C gene and stressful life events on suicide attempt risk in patients with major psychiatric disorders. World J. Biol. Psychiatry 16, 261-271. doi: 10.3109/15622975.2014.1000374

Kaster, M. P., Budni, J., Gazal, M., Cunha, M. P., Santos, A. R. S., and Rodrigues, A. L. S. (2013). The antidepressant-like effect of inosine in the FST is associated with both adenosine A1 and A2A receptors. Purinergic Signal. 9, 481-486. doi: 10.1007/s11302-013-9361-8

Kim, D., Zai, L., Liang, P., Schaffling, C., Ahlborn, D., and Benowitz, L. I. (2013). Inosine enhances axon sprouting and motor recovery after spinal cord injury. PLoS One 8:e81948. doi: 10.1371/journal.pone.0081948

Kovács, Z., Kékesi, K. A., Dobolyi, Á, Lakatos, R., and Juhász, G. (2015a). Absence epileptic activity changing effects of non-adenosine nucleoside inosine, guanosine and uridine in Wistar Albino Glaxo Rijswijk rats. Neuroscience 300, 593-608. doi: 10.1016/j.neuroscience.2015.05.054

Kovács, Z., Kékesi, K. A., Juhász, G., and Dobolyi, Á (2015b). Modulatory effects of inosine, guanosine and uridine on lipopolysaccharide-evoked increase in spikewave discharge activity in Wistar Albino Glaxo/Rijswijk rats. Brain Res. Bull. 118, 46-57. doi: 10.1016/j.brainresbull.2015.09.003

Lagerqvist, B., Sylvén, C., Hedenström, H., and Waldenström, A. (1990). Intravenous adenosine but not its first metabolite inosine provokes chest pain in healthy volunteers. J. Cardiovasc. Pharmacol. 16, 173-176. doi: 10.1097/ 00005344-199007000-00023

Lakátos, R. K., Dobolyi, Á, and Kovács, Z. (2018). Uric acid and allopurinol aggravate absence epileptic activity in Wistar Albino Glaxo Rijswijk rats. Brain Res. 1686, 1-9. doi: 10.1016/j.brainres.2018.02.012

Lapa, F. R., de Oliveira, A. P., Accetturi, B. G., de Oliveira Martins, I., Domingos, H. V., de Almeida Cabrini, D., et al. (2013). Anti-inflammatory effects of inosine in allergic lung inflammation in mice: evidence for the participation of adenosine A2A and A3 receptors. Purinergic Signal. 9, 325-336. doi: 10.1007/ s11302-013-9351-x

Lapin, I. P. (1981). Nicotinamide, inosine and hypoxanthine, putative endogenous ligands of the benzodiazepine receptor, opposite to diazepam are much more effective against kynurenine-induced seizures than against pentylenetetrazolinduced seizures. Pharmacol. Biochem. Behav. 14, 589-593. doi: 10.1016/00913057(81)90117-9

Lara, D. R., Dall'Igna, O. P., Ghisolfi, E. S., and Brunstein, M. G. (2006). Involvement of adenosine in the neurobiology of schizophrenia and its therapeutic implications. Prog. NeuroPsychopharmacol. Biol. Psychiatry 30, 617629. doi: 10.1016/j.pnpbp.2006.02.002

Lehmann, A. (1987). Alterations in hippocampal extracellular amino acids and purine catabolites during limbic seizures induced by folate injections into the rabbit amygdala. Neuroscience 22, 573-578. doi: 10.1016/0306-4522(87)90 354-x

Lewin, E., and Bleck, V. (1981). Electroshock seizures in mice: effect on brain adenosine and its metabolites. Epilepsia 22, 577-581. doi: 10.1111/j.1528-1157. 1981.tb04129.x

Lewin, E., and Bleck, V. (1985). Effect of inosine on seizures induced with pentylenetetrazole, bicuculline, or picrotoxin. Epilepsia 26, 258-261. doi: 10. 1111/j.1528-1157.1985.tb05415.x

Liaudet, L., Mabley, J. G., Pacher, P., Virág, L., Soriano, F. G., and Marton, A. (2002). Inosine exerts a broad range of antiinflammatory effects in a murine model of acute lung injury. Ann. Surg. 235, 568-578. doi: 10.1097/00000658-20020400000016

MacDonald, J. F., Barker, J. L., Paul, S. M., Marangos, P. J., and Skolnick, P. (1979). Inosine may be an endogenous ligand for benzodiazepine receptors on cultured spinal neurons. Science 205, 715-717. doi: 10.1126/science.37602

Macedo-Junior, S. J., Nascimento, F. P., Luiz-Cerutti, M., and Santos, A. R. S. (2013). Role of pertussis toxin-sensitive G-protein, K+ channels, and voltagegated Ca 2+ channels in the antinociceptive effect of inosine. Purinergic Signal. 9, 51-58. doi: 10.1007/s11302-012-9327-2

Macedo-Júnior, S. J., Nascimento, F. P., Luiz-Cerutti, M., and Santos, A. R. S. (2021). The role of peripheral adenosine receptors in glutamate-induced pain nociceptive behavior. Purinergic Signal. 17, 303-312. doi: 10.1007/s11302-02109781-y

Malewska-Kasprzak, M. K., Permoda-Osip, A., and Rybakowski, J. (2019). Disturbances of purinergic system in affective disorders and schizophrenia. Psychiatr. Pol. 53, 577-587. doi: 10.12740/PP/97335

Marangos, P. J., Martino, A. M., Paul, S. M., and Skolnick, P. (1981). The benzodiazepines and inosine antagonize caffeine-induced seizures. Psychopharmacology (Berl) 72, 269-273. doi: 10.1007/BF00431829

Marshall, G. F., Gonzalez-Sulser, A., and Abbott, C. M. (2021). Modelling epilepsy in the mouse: challenges and solutions. Dis. Model. Mech. 14:dmm047449. doi: $10.1242 / \mathrm{dmm} .047449$

McFarland, N. R., Burdett, T., Desjardins, C. A., Frosch, M. P., and Schwarzschild, M. A. (2013). Postmortem brain levels of urate and precursors in Parkinson's disease and related disorders. Neurodegener. Dis. 12, 189-198. doi: 10.1159/ 000346370

McNaughton, L., Dalton, B., and Tarr, J. (1999). Inosine supplementation has no effect on aerobic or anaerobic cycling performance. Int. J. Sport Nutr. 9, 333-344. doi: 10.1123/ijsn.9.4.333

Mocking, R. J. T., Naviaux, J. C., Li, K., Wang, L., Monk, J. M., Bright, A. T., et al. (2021). Metabolic features of recurrent major depressive disorder in remission, and the risk of future recurrence. Transl. Psychiatry 11:37. doi: 10.1038/s41398020-01182-w

Moore, T. L., Pessinaa, M. A., Finklesteind, S. P., Killianya, R. J., Bowleya, B., Benowitze, L., et al. (2016). Inosine enhances recovery of grasp following cortical injury to the primary motor cortex of the rhesus monkey. Restor. Neurol. Neurosci. 34, 827-848. doi: 10.3233/RNN-160661

Moscoso-Castro, M., Gracia-Rubio, I., Ciruela, F., and Valverde, O. (2016). Genetic blockade of adenosine A2A receptors induces cognitive impairments and anatomical changes related to psychotic symptoms in mice. Eur. Neuropsychopharmacol. 26, 1227-1240. doi: 10.1016/j.euroneuro.2016.04.003

Muto, J., Lee, H., Lee, H., Uwaya, A., Park, J., Nakajima, S., et al. (2014). Oral administration of inosine produces antidepressant-like effects in mice. Sci. Rep. 4:4199. doi: 10.1038/srep04199 
Nascimento, F. P., Figueredo, S. M., Marcon, R., Martins, D. F., Macedo, S. J., Lima, D. A., et al. (2010). Inosine reduces pain-related behavior in mice: involvement of adenosine A1 and A2A receptor subtypes and protein kinase C pathways. J. Pharmacol. Exp. Ther. 334, 590-598. doi: 10.1124/jpet.110. 166058

Nascimento, F. P., Macedo-Júnior, S. J., Pamplona, F. A., Luiz-Cerutti, M., Córdova, M. M., Constantino, L., et al. (2015). Adenosine A1 receptordependent antinociception induced by inosine in mice: pharmacological, genetic and biochemical aspects. Mol. Neurobiol. 51, 1368-1378. doi: 10.1007/ s12035-014-8815-5

North, R. A., and Verkhratsky, A. (2006). Purinergic transmission in the central nervous system. Pflugers Arch. 452, 479-485. doi: 10.1007/s00424-006-0060-y

O’Donovan, S. M., Sullivan, C., Koene, R., Devine, E., Hasselfeld, K., Moody, C. L., et al. (2018). Cell-subtype-specific changes in adenosine pathways in schizophrenia. Neuropsychopharmacology 43, 1667-1674. doi: 10.1038/s41386018-0028-6

Ohisalo, J. J., Murros, K., Fredholm, B. B., and Hare, T. A. (1983). Concentrations of gamma-aminobutyric acid and adenosine in the CSF in progressive myoclonus epilepsy without Lafora's bodies. Arch. Neurol. 40, 623-625. doi: 10.1001/ archneur.1983.04050090059009

Okada, S., Sakurai, M., Ueda, H., and Suzuki, T. (2015). Transcriptome-wide identification of A-to-I RNA editing sites by ICE-Seq. Methods 156, 66-78. doi: 10.1016/j.ymeth.2018.12.007

Okuyama, E., Ebihara, H., Takeuchi, H., and Yamazaki, M. (1998). Adenosine, the anxiolytic-like principle of the Arillus of Euphoria longana. Planta Med. 65, 115-119. doi: 10.1055/s-1999-14055

Ossowska, K., Kosmowska, B., and Wardas, J. (2020). Potential antipsychotic action of the selective agonist of adenosine A1 receptors, $5^{\prime}-\mathrm{Cl}-5^{\prime}$-deoxy-ENBA, in amphetamine and MK-801 rat models. Pharmacol. Rep. 72, 580-588. doi: 10. 1007/s43440-020-00093-3

Pacheco, S. M., Soares, M. S. P., Gutierres, J. M., Gerzson, M. F. B., Carvalho, F. B., Azambuja, J. H., et al. (2018). Anthocyanins as a potential pharmacological agent to manage memory deficit, oxidative stress and alterations in ion pump activity induced by experimental sporadic dementia of Alzheimer's type. J. Nutr. Biochem. 56, 193-204. doi: 10.1016/j.jnutbio.2018.02.014

Paganoni, S., and Schwarzschild, M. A. (2017). Urate as a marker of risk and progression of neurodegenerative disease. Neurotherapeutics 14, 148-153. doi: 10.1007/s13311-016-0497-4

Paul, S. M., Marangos, P. J., Goodwin, F. K., and Skolnick, P. (1980). Brainspecific benzodiazepine receptors and putative endogenous benzodiazepinelike compounds. Biol. Psychiatry 15, 407-428.

Petrausch, B., Tabibiazar, R., Roser, T., Jing, Y., Goldman, D., Stuermer, C. A., et al. (2000). A purine-sensitive pathway regulates multiple genes involved in axon regeneration in goldfish retinal ganglion cells. J. Neurosci. 20, 8031-8041. doi: 10.1523/JNEUROSCI.20-21-08031.2000

Ralevic, V., and Burnstock, G. (1998). Receptors for purines and pyrimidines. Pharmacol. Rev. 50, 413-492.

Ruhal, P., and Dhingra, D. (2018). Inosine improves cognitive function and decreases aging-induced oxidative stress and neuroinflammation in aged female rats. Inflammopharmacology 26, 1317-1329. doi: 10.1007/s10787-018-0476-y

Sawynok, J. (1998). Adenosine receptor activation and nociception. Eur. J. Pharmacol. 347, 1-11. doi: 10.1016/s0014-2999(97)01605-1

Sawynok, J., and Liu, X. J. (2003). Adenosine in the spinal cord and periphery: release and regulation of pain. Prog. Neurobiol. 69, 313-340. doi: 10.1016/s03010082(03)00050-9

Schmidt, A. P., Böhmer, A. E., Soares, F. A., Posso, I. P., Machado, S. B., Mendes, F. F., et al. (2010). Changes in purines concentration in the cerebrospinal fluid of patients experiencing pain: a case-control study. Neurosci. Lett. 474, 69-73. doi: 10.1016/j.neulet.2010.02.067

Schwarzschild, M. A., Ascherio, A., Beal, M. F., Cudkowicz, M. E., Curhan, G. C., Hare, J. M., et al. (2014). Inosine to increase serum and cerebrospinal fluid urate in Parkinson disease: a randomized clinical trial. JAMA Neurol. 71, 141-150. doi: 10.1001/jamaneurol.2013.5528

Schwarzschild, M. A., Macklin, E. A., Bakshi, R., Battacharyya, S., Logan, R., Espay, A. J., et al. (2019). Sex differences by design and outcome in the Safety of Urate Elevation in PD (SURE-PD) trial. Neurology 93, e1328-e1338. doi: 10.1212/ WNL.0000000000008194
Silberg, G., Lundin, D., Navon, R., and Öhman, M. (2011). Deregulation of the A-to-I RNA editing mechanism in psychiatric disorders. Hum. Mol. Genet. 21, 311-321. doi: 10.1093/hmg/ddr461

Skolnick, P., Marangos, P. J., Goodwin, F. K., Edwards, M., and Paul, S. (1978). Identification of inosine and hypoxanthine as endogenous inhibitors of [3H] diazepam binding in the central nervous system. Life Sci. 23, 1473-1480. doi: 10.1016/0024-3205(78)90128-5

Skolnick, P., Syapin, P. J., Paugh, B. A., Moncada, V., Marangos, P. J., and Paul, S. M. (1979). Inosine, an endogenous ligand of the brain benzodiazepine receptor, antagonizes pentylenetetrazole-evoked seizures. Proc. Natl. Acad. Sci. U.S.A. 76, 1515-1518. doi: 10.1073/pnas.76.3.1515

Slater, P., and Longman, D. A. (1979). Effects of diazepam and muscimol on GABAmediated neurotransmission: interactions with inosine and nicotinamide. Life Sci. 25, 1963-1967. doi: 10.1016/0024-3205(79)90599-x

Smith, J. M., Lunga, P., Story, D., Harris, N., Le Belle, J., James, M. F., et al. (2007). Inosine promotes recovery of skilled motor function in a model of focal brain injury. Brain 130, 915-925. doi: 10.1093/brain/awl393

Teixeira, F. C., Gutierres, J. M., Soares, M. S. P., Mattos, B. S., Spohr, L., do Couto, C. A. T., et al. (2020). Inosine protects against impairment of memory induced by experimental model of Alzheimer disease: a nucleoside with multitarget brain actions. Psychopharmacology 237, 811-823. doi: 10.1007/s00213-01905419-5

Tilley, S. L., Wagoner, V. A., Salvatore, C. A., Jacobson, M. A., and Koller, B. H. (2000). Adenosine and inosine increase cutaneous vasopermeability by activating $\mathrm{A}(3)$ receptors on mast cells. J. Clin. Invest. 105, 361-367. doi: 10. 1172/JCI8253

Wagner, J. A., and Katz, R. J. (1983). Purinergic control of anxiety: direct behavioral evidence in the rat. Neurosci. Lett. 43, 333-337. doi: 10.1016/0304-3940(83) 90210-0

Welihinda, A. A., Kaur, M., Greene, K., Zhai, Y., and Amento, E. P. (2016). The adenosine metabolite inosine is a functional agonist of the adenosine A2A receptor with a unique signaling bias. Cell. Signal. 28, 552-560. doi: 10.1016/ j.cellsig.2016.02.010

Williams, M. H., Kreider, R. B., Hunter, D. W., Somma, C. T., Shall, L. M., Woodhouse, M. L., et al. (1990). Effect of inosine supplementation on 3mile treadmill run performance and VO2 peak. Med. Sci. Sports Exerc. 22, 517-522.

Xiao, X., Dawson, N., MacIntyre, L., Morris, B. J., Pratt, J. A., and Watson, D. G. (2011). Exploring metabolic pathway disruption in the subchronic phencyclidine model of schizophrenia with the Generalized Singular Value Decomposition. BMC Syst. Biol. 5:72. doi: 10.1186/1752-050 9-5-72

Yamazaki, T., Kishimoto, K., and Ezaki, O. (2012). The ddY mouse: a model of postprandial hypertriglyceridemia in response to dietary fat. J. Lipid Res. 53, 2024-2037. doi: 10.1194/jlr.M023713

Yarom, M., Tang, X. W., Wu, E., Carlson, R. G., Vander Velde, D., Lee, X., et al. (1998). Identification of inosine as an endogenous modulator for the benzodiazepine binding site of the GABAA receptors. J. Biomed. Sci. 5, 274-280. doi: 10.1007/BF02255859

Yuan, S., Jiang, X., Zhou, X., Zhang, Y., Teng, T., and Xie, P. (2018). Inosine alleviates depression-like behavior and increases the activity of the ERK-CREB signaling in adolescent male rats. Neuroreport 29, 1223-1229. doi: 10.1097/ WNR.0000000000001101

Zai, L., Ferrari, C., Dice, C., Subbaiah, S., Havton, L. A., Coppola, G., et al. (2011). Inosine augments the effects of a Nogo receptor blocker and of environmental enrichment to restore skilled forelimb use after stroke. J. Neurosci. 31, 59775988. doi: 10.1523/jneurosci.4498-10.2011

Zai, L., Ferrari, C., Subbaiah, S., Havton, L. A., Coppola, G., and Strittmatter, S. (2009). Inosine alters gene expression and axonal projections in neurons contralateral to a cortical infarct and improves skilled use of the impaired limb. J. Neurosci. 29, 8187-8197. doi: 10.1523/JNEUROSCI.0414-09. 2009

Zhou, X., Liu, L., Lan, X., Cohen, D., Zhang, Y., Ravindran, A. V., et al. (2019). Polyunsaturated fatty acids metabolism, purine metabolism and inosine as potential independent diagnostic biomarkers for major depressive disorder in children and adolescents. Mol. Psychiatry 24, 1478-1488. doi: 10.1038/s41380018-0047-z 
Zurn, A. D., and Do, Q. K. (1988). Purine metabolite inosine is an adrenergic neurotrophic substance for cultured chicken sympathetic neurons. Proc. Natl. Acad. Sci. U.S.A. 85, 8301-8305. doi: 10.1073/pnas.85.21.8301

Conflict of Interest: The authors declare that the research was conducted in the absence of any commercial or financial relationships that could be construed as a potential conflict of interest.

Publisher's Note: All claims expressed in this article are solely those of the authors and do not necessarily represent those of their affiliated organizations, or those of the publisher, the editors and the reviewers. Any product that may be evaluated in this article, or claim that may be made by its manufacturer, is not guaranteed or endorsed by the publisher.

Copyright (C) 2021 Nascimento, Macedo-Júnior, Rocha Lapa-Costa, Cezar-dos-Santos and Santos. This is an open-access article distributed under the terms of the Creative Commons Attribution License (CC BY). The use, distribution or reproduction in other forums is permitted, provided the original author(s) and the copyright owner(s) are credited and that the original publication in this journal is cited, in accordance with accepted academic practice. No use, distribution or reproduction is permitted which does not comply with these terms. 